and on 300 deer culled from outside the fence should reveal whether CWD has truly breached the Rockies.

Ranching has almost certainly contributed to the spread of CWD. The elk industry exploded in the early 1990s when the animal's velvet antlers, valued in traditional Asian medicine, began to attract prices of up to $\$ 200$ a kilogram on the international market. Ranchers in the United States and Canada then began to keep the animals in large numbers. Long-distance rapid transport of commercial elk is speeding the spread of a disease that moved slowly among wild animals, Malmsbury says.

Because the only definitive test for CWD is an examination of the brain stem, surveillance programmes rely on samples from slaughtered or hunted animals, and infected herds are often spotted only after some members have been shipped away. Although it is possible to trace sales of live elk, some states have only recently started requiring ranchers to keep such records. Other states, such as Iowa, operate no surveillance of CWD.

In theory, CWD could be present in the wild at low levels outside the known endemic area without being noticed, says Sam Holland, chief veterinarian of South Dakota. Ranching might bring it to the fore because the disease would spread faster in a concentrated herd. "I don't think anyone knows whether it exists at a low level in populations out there or not," he says.

\title{
Disbelief greets claim for creation of first human clone
}

\section{Alison Abbott}

European scientists have voiced scepticism about claims by the Italian gynaecologist Severino Antinori that one of his patients is two-months pregnant with a cloned human embryo.

Antinori, who is director of the infertility unit at the International Associated Research Institute for Human Reproduction in Rome, made the announcement to the newspaper Gulf News last week, when he attended a meeting on human genetics in the United Arab Emirates.

One Italian newspaper, Il Tempo, said that Antinori had confirmed the claim, but he has refused to comment to other journalists, saying only that "research needs silence". Glasgow's Sunday Herald, meanwhile, reported that Antinori had split with his long-time collaborator, Panos Zavos of the Andrology Institute of America in Lexington, Kentucky, and that Zavos was pursuing his own cloning programme independently in Cyprus.

"There is, of course, some scepticism that the cloning has really been done," says Carlo Redi, an animal-cloning expert at the University of Pavia. Although the work is alleged to have been done outside Europe, if it has taken place, he says, it contravenes both the law in Italy and normal codes of medical practice. Studies in animals have shown that cloning yields few successful births, and that a high proportion of the offspring produced are born with defects. The Italian Medical Association has issued several threats to expel Antinori, but has not yet done so.

Caution is also apparent outside Italy. "It is theoretically possible," says Eckhard Wolf, a cloning expert from the University of Munich, but he adds that "even if Antinori has achieved a pregnancy, the rate of spontaneous abortion in the second trimester of pregnancy is very high, so comments are premature."

More bluntly, Ian Wilmut of Edinburgh's Roslin Institute, a member of the team that cloned Dolly the sheep, says that Antinori's claim is "either a misunderstanding or deliberately misleading”. The biggest danger, he says, is that Antinori's activities will generate public anxiety about cloning, turning people against the idea of using 'therapeutic cloning' for regenerative medicine.

In Italy, scientists fear that the news could adversely affect the public mood just as a bill to regulate the use of embryonic stem cells and of therapeutic medicine is to be debated in parliament. "We worry that it may increase pressure for a very restrictive law," says Redi.

\section{Court rules out Italian research appointment}

\section{Sally Goodman}

Italy's national research council, the CNR, has been found guilty of unfair treatment towards an Italian astrophysicist during the selection process for a directorship at one of its institutes.

The court ruling could have wide implications for the other appointments so far made in the CNR's international recruitment drive to find leaders for 100 of its institutes (see Nature 414, 133; 2001).

Giovanni Bignami, currently research director of the Italian space agency, ASI, was interviewed for the directorship of the newly created Institute of Astrophysics and Cosmic Physics last October. But the post was awarded to the director of the Institute for Extraterrestrial Radiation in Bologna, one of four centres making up the new astrophysics institute.

Bignami challenged the appointment in a Rome court on the grounds that the CNR had not followed the correct procedure during the selection process. He argued that the research agency had failed to make sure that the nine-member executive council of the CNR, which makes such appointments, received proper advice from specialists on the candidates' qualifications.

"It was a blatant case of injustice," says Bignami. The court decision, issued on 4 April, overturns last autumn's appointment and will probably force the CNR to rerun the recruitment process.

Reactions to the judgement were mixed. Arturo Falaschi director of the International Centre for Genetic Engineering and Biotechnology in Trieste, a member of the council who voted for Bignami, says that the court's judgement sets a "terrible precedent". He insists that the CNR went out of its way to make the recruitment process public and transparent. "I believe Bignami was the best person for the job," he says, "but due process was followed and the final decision was legitimate."

But an adviser to the research and education ministry says that he was unhappy about the way the CNR had handled the appointment and is pleased with the court's judgement. "The CNR and

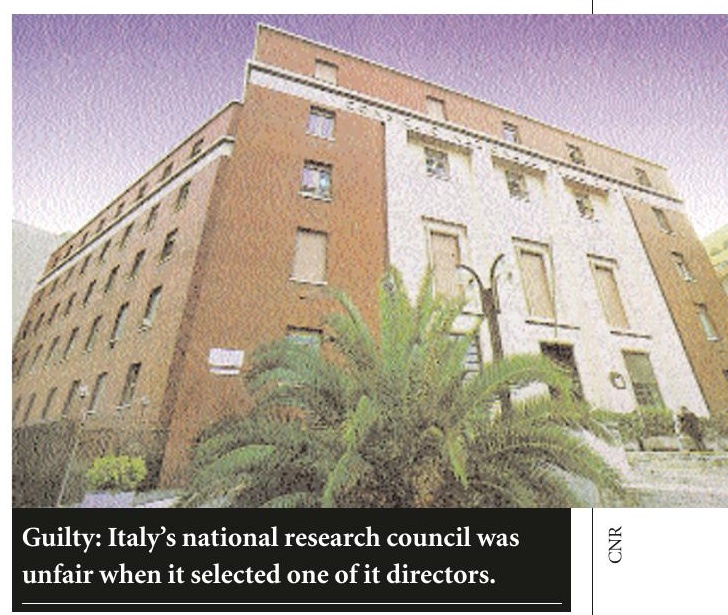

the ministry should now be questioning why this has happened. Other nominations may now have to be cancelled," the adviser says.

A spokesperson for Lucio Bianco, the CNR's president, said that Bianco would not comment until he had read the full text of the judgement which, as Nature went to press, had yet to be released by the court. 